\title{
An assessment of the barriers to accessing food among food-insecure people in Cobourg, Ontario
}

\author{
S. Tsang, MHSc, RD (1); A.M. Holt, MHSc (2); E. Azevedo, MSc, RD (1)
}

\begin{abstract}
Introduction: Low-income people are most vulnerable to food insecurity; many turn to community and/or charitable food programs to receive free or low-cost food. This needs assessment aims to collect information on the barriers to accessing food programs, the opportunities for improving food access, the barriers to eating fresh vegetables and fruit, and the opportunities to increasing their consumption among food-insecure people in Cobourg, Ontario.
\end{abstract}

Methods: We interviewed food program clients using structured individual interviews consisting of mostly opened-ended questions.

Results: Food program clients identified barriers to using food programs as lack of transportation and the food programs having insufficient quantities of food or inconvenient operating hours. They also stated a lack of available vegetables and fruit at home, and income as barriers to eating more vegetables and fruit, but suggested a local fresh fruit and vegetable bulk-buying program called "Good Food Box" and community gardens as opportunities to help increase their vegetable and fruit intake.

Discussion: Many of the barriers and opportunities identified can be addressed by working with community partners to help low-income individuals become more food secure.

Keywords: nutrition, low-income population, poverty, healthy food, accessibility, fruit, vegetables, food insecurity, Ontario

\section{Introduction}

The link between low-income and health is well documented: people at the lowest socio-economic level are at risk of developing chronic diseases, including heart disease, diabetes, chronic respiratory diseases and cancer, and of dying prematurely. ${ }^{1-13}$ Previous studies report that income greatly impacts food accessibility, which in turn influences food consumption, especially of nutritious food required to keep healthy. ${ }^{14-19}$ Individuals who have limited physical and economic access to safe, nutritious, and
In Ontario, $47.2 \%$ of households earning less than $\$ 10,000$ before tax are food insecure, compared to only $1.8 \%, 5.2 \%$ and $14.4 \%$ for households in the highest, upper middle, and middle-income categories, respectively. ${ }^{23}$ Food-insecure individuals turn to community food programs, such as community gardens and kitchens, or charitable food programs, such as food banks, or both, to receive free or low-cost food to help alleviate some of their financial constraints.

The purpose of this needs assessment is to collect information on the barriers to accessing food programs, whether community- or charity-based; the opportunities for improving food access; the barriers to eating vegetables and fruit; and the opportunities to increasing the consumption of vegetables and fruit among food-insecure people in Cobourg, Ontario.

\section{Background}

Cobourg is located in the province of Ontario, approximately 110 kilometres east of Toronto. It is the largest urban-like centre in Northumberland County, which is made up of mostly rural communities. The population in 2006 was 18 210, with the majority aged over 25 years. ${ }^{24}$ At that time it was home to 5235 families, with $18 \%$ of these being single-parent families. ${ }^{24}$ The unemployment rate was $6.7 \%$, compared to $6.4 \%$ for Ontario. ${ }^{24}$ About 7\% of Cobourg's population was low-income before tax. ${ }^{24}$

Cobourg has a public transportation system of two fixed bus routes. There are four major grocery chain stores, two of which

Author references

1. Chronic Disease \& Injury Prevention Department; Haliburton, Kawartha, Pine Ridge District Health Unit, Port Hope, Ontario, Canada

2. Epidemiology \& Evaluation Services; Haliburton, Kawartha, Pine Ridge District Health Unit, Port Hope, Ontario, Canada

Correspondence: Sarah Tsang, Public Health Dietitian, Chronic Disease and Injury Prevention Department, Haliburton, Kawartha, Pine Ridge District Health Unit, 200 Rose Glen Road;

Port Hope ON L1A 3V6; Tel.: (905) 885-9100 ext 497; Fax: (905) 885-9551; Email: stsang@hkpr.on.ca 
are discount food stores. There is one food bank, one free lunch program, one community garden, and a handful of charitable community organizations that manage pantries of donated foods that are available for free to any food-insecure person. The food bank is open every Wednesday and Friday for three hours in the morning, and clients are able to access it two times per month. The free lunch program is available every day of the week for one hour to anyone in need. Charitable community organizations that manage food pantries are opened during their normal business hours.

\section{Methods}

We used a convenience sample to gather information from adults who had used services such as food banks and counselling programs at least once.

Potential respondents were recruited at two local non-governmental organizations that manage charitable food programs but whose primary mandate is not the provision of food. We chose these particular charitable food programs because they are located in safe and friendly neighbourhoods, which facilitated the recruitment and the interview process. Also, these two organizations reach people who use any of the available charitable food programs, as well as a broader spectrum of food-insecure people. Four members of a local food security committee volunteered to be trained to conduct interviews. The needs assessment was advertised on flyers posted at the designated locations. Interview respondents were recruited using two different sampling strategies: at one location, two trained interviewers approached food program clients with a standard script; at the other, an individual who had a relationship with many of the food program clients facilitated recruitment of potential respondents. Both recruitment methods requested voluntary participation. Potential respondents were told of the purpose of the needs assessment and assured confidentiality; consent was verbal. They were shown to a quiet corner or a separate room to be interviewed by the two trained interviewers using the interview guide. In total, 35 people completed the interview, after which every respondent received an information letter describing the needs assessment and detailing the consent process.

The interview guide consisted of structured, open-ended questions and several closedended questions. Prior to starting this needs assessment, the interview guide was reviewed by a member of the local food security committee and health unit staff, and piloted-tested with a sample of food bank recipients from another municipality. The questions were about barriers to using and opportunities for improving access to food programs; barriers to and opportunities for eating vegetables and fruit; and the respondents' own definitions of what it means to have enough food. The interviewers took notes of the respondents' keywords and phrases, or explanations of their answers, and recorded descriptions of their body language to provide additional context to the answer. The interviewers checked the trustworthiness of the data they had recorded by periodically repeating the response to verify their understanding and interpretation of what the respondents had said.

At the end of each day, all the interviewers were debriefed so as to analyze the written responses and the interviewers' thoughts, feelings and insights about each interview.

The needs assessment protocol was reviewed for ethical consideration in accordance with established standards of the Haliburton, Kawartha, Pine Ridge District Health Unit.

\section{Data analysis}

Using framework analysis, we qualitatively analyzed all the responses to open-ended questions and all field notes recorded for both open- and closed-ended questions. ${ }^{25}$ Framework analysis is a qualitative method ideally suited to studies with specific questions, a limited time frame, a convenience sample and a priori objectives, such as the barriers and opportunities assessed in our study. ${ }^{26}$ Tallies and percentages to each closed-ended question and the demographics were calculated separately. The data were analyzed throughout and after the data collection process, enabling the lead researcher to identify the point when data saturation was reached.
Using La Pelle's methods, answers and field notes to all interview questions were entered into a table formatted in Microsoft Word. ${ }^{27}$ Data were coded using a thematic framework developed a priori from the needs assessment objectives. ${ }^{25}$ Expressions indicating barriers or opportunities were marked with colours and different fonts. A separate document was created to group all expressions of barriers and opportunities together. ${ }^{28}$ The grouped expressions were then separated into (1) barriers and opportunities according to their question number and reference to food programs in general; (2) reasons for accessing food programs more than once a month; and (3) vegetables and fruit consumption. These distinct clusters were then analyzed for common subthemes.

One question from the standard script interview, "What does 'having enough food' mean to you?" did not fit into the a priori framework. Rather, the question gave context and meaning to food insecurity as experienced locally by individuals and households. For this question, themes were generated as they surfaced from the data without the use of an a priori framework.

All of the raw data were analyzed independently by two investigators using the same framework, and their analysis was reviewed by a third. The three investigators discussed any discrepancies to reach a consensus on the categories.

\section{Results}

Table 1 shows the characteristics and the household make-up of the respondents.

Of the 35 respondents who completed an interview, $43 \%$ said that if there were no restrictions, they wished they could access food programs once a week (data not shown). All of the respondents said they enjoy eating vegetables, while $97 \%$ said they enjoy eating fruit. Only $23 \%$ said they are able to get as much vegetables and fruit as they want.

\section{Barriers to using food programs}

The most common barrier mentioned by the respondents was transportation, as 14 respondents (40\%) either lacked the means 
TABLE 1

Characteristics of respondents $(\mathrm{N}=35)$ who completed a needs assessment interview about barriers to accessing food programs and to eating vegetables and fruit.

\begin{tabular}{|c|c|c|}
\hline Group & $\begin{array}{c}\text { Number of respondents, } \\
n\end{array}$ & $\begin{array}{c}\text { Percentage of respondents, } \\
\%\end{array}$ \\
\hline \multicolumn{3}{|l|}{ Sex } \\
\hline Female & 31 & 89 \\
\hline Male & 4 & 11 \\
\hline \multicolumn{3}{|l|}{ Age } \\
\hline 18-29 years & 5 & 14 \\
\hline $30-39$ years & 12 & 34 \\
\hline $40-49$ years & 12 & 34 \\
\hline $50-59$ years & 5 & 14 \\
\hline $60-69$ years & 1 & 3 \\
\hline $70+$ years & 0 & 0 \\
\hline \multicolumn{3}{|l|}{ Place of residence } \\
\hline Cobourg & 30 & 86 \\
\hline Outside Cobourg & 5 & 14 \\
\hline \multicolumn{3}{|l|}{ Interview request approach } \\
\hline Interviewers approached potential respondents directly & 9 & 26 \\
\hline $\begin{array}{l}\text { Interviewers introduced to potential respondents by an individual who had } \\
\text { a relationship with the respondents }\end{array}$ & 26 & 74 \\
\hline \multicolumn{3}{|l|}{ Children in the household ${ }^{a}$} \\
\hline None & 12 & 34 \\
\hline Children 12 years and under & 18 & 51 \\
\hline Children $13-18$ years & 10 & 29 \\
\hline \multicolumn{3}{|l|}{ People working in the household } \\
\hline 0 & 13 & 37 \\
\hline 1 & 15 & 43 \\
\hline 2 & 5 & 14 \\
\hline 3 & 2 & 6 \\
\hline \multicolumn{3}{|l|}{ Source of household income ${ }^{b}$} \\
\hline Ontario Works & 10 & 29 \\
\hline Ontario Disability Support Program & 11 & 31 \\
\hline Ontario Child Care Supplement for Working Families & 5 & 14 \\
\hline Canada Pension Plan Disability (CPPD) & 0 & 0 \\
\hline Canada Pension Plan (CPP) & 3 & 9 \\
\hline Old Age Security Program & 2 & 6 \\
\hline Ontario Student Assistance Program & 0 & 0 \\
\hline Regular employment & 22 & 63 \\
\hline Employment Insurance (EI) & 22 & 63 \\
\hline Workplace Safety and Insurance Board (WSIB) Benefits & 0 & 0 \\
\hline Other & 2 & 6 \\
\hline None & 0 & 0 \\
\hline
\end{tabular}

a Some households include children in both age groups (less than 12 years, 13-18 years), hence the percentages add up to more than 100.

${ }^{\mathrm{b}}$ Some households have more than one source of income, hence the percentages add up to more than 100 . 
to get to the program location (no vehicle, no access to rides) or had difficulty walking home with large boxes of food. Certain foodstuffs in the food banks, such as milk, pasta, and peanut butter, were quickly depleted, and 6 respondents (17\%) mentioned that they receive insufficient quantities of food for themselves and their household. One single, middle-aged woman exclaimed about the food banks' food supply in general, "It's the food-running out of food all the time." Another respondent, a mother of two younger children and two teenagers, explained, “The food bank don't [sic] give enough food." Ten respondents (29\%) complained that the food programs are not open for long enough during the day or throughout the month, and that the times of operation conflict with their personal schedules. One woman explained the current operation of the food bank: "[the food bank] now opens 10 [a.m.] to 1 [p.m.], but [I] would like [it to be open] from 9 [a.m.] to 4 [p.m.]." Other barriers were not knowing where food programs are located throughout the community; the quality of food, which is described as being mostly "junk food;" the need to show personal identification; not being able to choose preferred food; and that the food bank service area was too small and could not be accessed by people in wheelchairs or with children in strollers. Regarding food quality, a mother of two recounted, "I got home once to find 50 percent or more [of the food from the food bank] are [sic] fruit cakes, doughnuts, cookies, and I cried... I thought, how can I feed my child?"

\section{Opportunities for improving food program access}

Three respondents suggested opening food programs on more days of the week and during morning, afternoon and evening hours. One mother of three said, "Most programs [are] open Monday, Wednesday, Friday...[It would be] nice if something [was] available other than those days." Several others expressed the theme of social support networks, where people help each other by growing food and sharing together or making sure there is enough food remaining for the next individual. A part-time working mother of two children explained her ideal barrier-free food bank system, "Have to be fair to other people-don't be greedy or selfish-don't be taking too much, just enough to get by." Finally, thirteen respondents $(37 \%)$ reported very few or no barriers to using food programs.

\section{Barriers to eating vegetables and fruit}

Twelve respondents (34\%) mentioned that not having enough vegetables and fruit was a barrier to eating them. A part-time working mother of one stated that she does not need encouragement to eat more vegetables and/or fruit. Rather, she said, “[I] don't eat them because I don't have them [in my home].” Another single mother of three explained why she does not eat more vegetables or fruit in the context of food insecurity, "If I knew I had enough for my boys, I myself would eat more." Not having enough money to afford vegetables or fruit, and vegetables and fruit being expensive were other common themes. When asked "What would encourage you to eat more vegetables and/or fruit", an unemployed, single, middle-aged man replied, “[I] don't make enough money. If I had more money, I' [d] make sure to buy some fruit." A working mother of two who is the sole breadwinner of the household described what might help her get more fruits and vegetables, "more money...they say [vegetables and fruit] are cheaper, but [they're] not."

\section{Opportunities for increasing consumption of vegetables and fruit}

Eleven respondents $(31 \%)$ suggested that the food program use or offer a local fresh fruit and vegetable bulk-buying program, the "Good Food Box,"* as a way to help increase their vegetable and fruit consumption. Sixteen respondents $(46 \%)$ stated that the affordability of vegetables and fruit and their availability at food programs are factors in how much they consume them. Ten respondents (29\%) mentioned having or joining a gardening program, or having a garden or more room to grow their own vegetables and fruits. Ten respondents (29\%) also mentioned that they would eat more vegetables and fruit if they knew more about the benefits of eating these, if they had recipes and/or took cooking classes, and if they knew how to keep vegetables and fruit longer without spoilage.

\section{Reasons for accessing food programs more than once a month}

Seven respondents (20\%) explained that they need to return to different food banks in the greater region several times each month because they do not receive enough food at any one particular location. A part-time working mother of two described her experience with a food bank, "We get one can of tomato soup for two weeks and a bag of pasta for a family of six...It's not enough!" Two respondents commented on the lack of variety of food at food banks; one full-time working mother of two explained why she visits several food outlets during the month, including food banks: “I don’t get balanced nutrition...I can't hit all four food groups going to food banks." Two respondents explained that visiting only one food bank limited their choice; one non-working mother of two teenagers stated, "[a certain food bank]-they decided for me...I don't need mushrooms, beans and tomatoes." Fourteen respondents (40\%) said that they wish they could access several food programs each week.

\section{Having enough food means...}

For fourteen respondents (40\%), having enough food meant being able to feed their children healthy, nutritious diets that included a variety of foods. A single, part-time employed mother of two had this to say about having enough food: “[It] doesn't even mean choice...have one thing from each food group to give to [the] children and myself at every meal-make do with what you have." Having peace of mind that "everyone in the family has all they need" and not worrying about budgeting or the children going hungry also represented having enough food. One part-time employed mother defined having enough food as "knowing there's enough food in the fridge or cupboard until the next time I'm getting a cheque." 
Five respondents (14\%) equated having an adequate amount of food to being able to eat several times in the day or allowing the children to eat as much food as they could. Seven respondents (20\%) also reported wanting to be able to eat healthy meals on a regular basis and "feed their entire family every day.”

\section{Discussion}

In this needs assessment, we found that (1) transportation, food quantity and food program hours limit food access; (2) that availability and income hinder vegetable and fruit consumption for food-insecure individuals; (3) that food quantity and quality caused respondents to visit food programs more than once a month; and that (4) being able to feed the children in the household adequate quantities of nutritious food was a common definition of having enough food.

Several studies assessing charitable food programs found that recipients commonly receive insufficient quantities of food and that what there is is of poor quality. ${ }^{29-31}$ Teron and Tarasuk assessed 85 food hampers received by Toronto Daily Food Bank clients and found that over half of the households with three or more persons received less than a three-day supply of food. ${ }^{29}$ In addition, over $78 \%$ of the food hampers contained at least one damaged or out-dated food item. ${ }^{29}$ Hamelin et al. suggested that for low-income food-insecure households meeting basic physical needs by having enough food to eat is just as important as having a diverse, balanced diet. ${ }^{32,33}$ Respondents in our needs assessment also expressed the importance of fulfilling their basic physical need through quantity and quality of food; not having this need met may be one of the reasons why almost half of the respondents wished they could access food programs and services more often, i.e. once a week.

Most of the respondents in our needs assessment were mothers. Other Canadian studies also found that it was vitally important to mothers that their children received optimal nutrition. ${ }^{33-36}$ They equated having enough food with providing for their children. These mothers go to great lengths to satisfy their children's hunger, opting to visit food programs several times each month, despite the stigma associated with using food banks and the feeling of loss of dignity $^{33,37}$.

Because food banks and other similar types of programs are so dependent on charity or donated products, there is no guarantee of the stock levels or type of foods distributed at any one location at a particular time. This makes them unreliable as a food outlet source for food-insecure individuals who depend on the programs simply to feed their families from day to day. 22,29,32,33

Many respondents said that transportation is a barrier to their using food programs. This finding is not exclusive to low-income individuals, as a recent study conducted with all Northumberland County residents reported transportation as one of the top three concerns in the county. ${ }^{38}$ For low-income individuals who barely get by paying for basic living necessities, public transportation is a luxury, ${ }^{39}$ and for the few who are able to afford a vehicle, these are typically unreliable or non-functioning. ${ }^{40}$ Our needs assessment indicated that walking is the primary or preferred mode of transportation because of its low cost; of course, carrying food supplies makes the return trip problematic. Exploring the experiences of lowincome mothers caring for children, Bostock pointed out that $82 \%$ of the mothers did not own a car and relied on walking to get to places; ${ }^{41}$ since they found walking stressful and physically tiring, they were confined to accessing only those resources that were within walking distance. In short, lack of transportation restricts an individual's way of life and their access to resources, such as the quantity of food one can carry back home.

In our needs assessment, many interviewees commented that they would eat more vegetables and fruit if such fresh produce was available in their homes. Further discussion revealed that the underlying reason for the lack of vegetables and fruit in the home is that fresh produce is unaffordable and not readily available through food programs. Previous studies show that individuals at the lowest socio-economic status tend to eat fewer vegetables and fruit than people of higher socio-economic status. ${ }^{42-48}$ Health
Canada recommends that adults aged 19 to 50 years eat a minimum of seven servings of vegetables and fruit daily. ${ }^{49}$ However, for those living on a low income, the price of vegetables and fruit often precludes eating the recommended number of servings. Along with other social determinants such as employment, housing, education, and access to services, income has a profound effect on individual health and the health of a community; ${ }^{50-52}$ some argue that it is the most important determinant of health. ${ }^{53,54}$

Although our findings are consistent with the literature on the barriers to food access, our study also has a number of limitations. First, to reduce intimidation and thus increase participation, interviews were not tape-recorded. The interviewers played a dual role as both interviewer and recorder. In such instances, interviewers may either elicit important information but forget to record it verbatim, or they may record diligently but forget to probe for clarification when necessary. There may also be interviewer bias as interviewers must quickly filter responses to note keywords, phrases, or sentences spoken by each respondent. This subjects the data to a preliminary level of sorting and analysis, which may vary slightly from interviewer to interviewer, and it is difficult to ascertain the extent to which interviewers have filtered the information.

Second, more interviews took place at one location than the other. Consequently, the sample population may not be representative of all food-insecure individuals.

Despite the limitations, this needs assessment has highlighted the need to address:

1) Food availability: working to ensure that certain types of food will be available at food programs and that sufficient quantities of food is given relative to household size;

2) Transportation: working to ensure that affordable public transportation is available to get to and from food program locations;

3) Supportive networks: working to enhance social networking opportunities so that people can support each other's needs; 
4) Local fresh fruit and vegetable bulk-buying program: working to ensure that the program is affordable especially for lowincome families and individuals.

5) Community gardening: working to generate interest and skills around community gardens to help increase vegetable and fruit intake.

Addressing these food access issues would present a new set of challenges that would need to be considered. It is crucial, then, that everyone, community partners and local communities alike, work together in a concerted effort to overcome the obstacles.

Programs such as food banks and soup kitchens were never meant to be long-term services. They were originally intended to temporarily relieve people facing economic trouble so that they could direct their finances towards bill payments and other basic living necessities. However, such programs have become permanent and will not be eliminated unless other socioeconomic factors, such as transportation, employment, education, childcare and affordable housing, are addressed in tandem. While there is still a long way to go in eliminating such social challenges, individuals in the interim can help break down barriers and reduce the risk factors of chronic diseases by addressing food access first. This research will help inform local decision-making and strengthen programming in the area of food security.

\section{Acknowledgements}

We would like to thank the Canadian Cancer Society, GTA Cancer Prevention and Screening Network for their financial support of this research. We would like to acknowledge the two non-governmental organizations where we recruited the respondents for their assistance with data collection and recruitment. We thank the participants who shared their experiences and stories with us. We would also like to acknowledge Ms. Lesley Hamilton, executive director of Literacy Ontario Central South, and Ms. Sasha Korper, early literacy consultant, for their assistance with the readability and literacy level of our information letter to participants. Finally, we would like to thank Dr. Gayle Broad, assistant professor at
Algoma University, Dr. Lynn Scruby, assistant professor of the Faculty of Nursing at University of Manitoba, and Dr. Valerie Tarasuk, professor of the Dalla Lana School of Public Health at University of Toronto for their comments on the preliminary research methodology.

\section{References}

1. Gordon D, Shaw M, Dorling D, Davey Smith G, editors. Inequalities in health: the evidence presented to the independent inquiry into inequalities in health. Bristol (UK): Policy Press; 1999. (Studies in poverty, inequality and social exclusion.)

2. Sram I, Ashton J. Millennium report to Sir Edwin Chadwick. Br Med J. 1998;317:592-6.

3. Pantazis C, Gordon D. Tackling inequalities: Where are we now and what can be done? Bristol (UK): Policy Press; 2000. (Studies in poverty, inequality and social exclusion.)

4. World Health Organization. Preventing chronic diseases: a vital investment [Internet]. Geneva $(\mathrm{CH})$ : World Health Organization; 2005 [cited 2010 Jan 27]. Available from: http://www.who.int/chp/chronic_disease _report/contents/en/index.html

5. Lynch J, Smith GD, Hillemeier M, Shaw M, Raghunathan T, Kaplan G. Income inequality, the psychosocial environment, and health: comparisons of wealthy nations. Lancet. 2001;358(9277):194-200.

6. Wilkins R, Berthelot JM, Ng E. Trends in mortality by neighbourhood income in urban Canada from 1971 to 1996 . Health Rep. 2002;13 Suppl: 45-71.

7. Gwatkin DR. Health inequalities and the health of the poor: what do we know? What can we do? Bull World Health Organ. 2000;78(1):3-18.

8. Williamson DL. The role of the health sector in addressing poverty. Can J Public Health. 2001;92(3):178-83.

9. Gyorfi-Dyke E. Poverty and chronic disease: recommendations for action [Internet]. Ottawa (ON): Chronic Disease Prevention Alliance of Canada; 2008 [cited 2010 Jan 27].
Available from: http://www.healthyenvironmentforkids.ca/sites/healthyenvironmentforkids.ca/files/cpche-resources/CDandPoverty_CDPAC.pdf

10. Archeson D. Independent inquiry into inequalities in health [Internet]. United Kingdom: Her Majesty Stationary Office; 1998 [cited 2009 Dec 9]. Available from: http://www.archive.official-documents.co.uk /document/doh/ih/ih.htm

11. Lightman E, Mitchell A, Wilson B. Poverty is making us sick: a comprehensive survey of income and health in Canada. Toronto (ON): Wellesley Institute; 2008.

12. Wilson B. Sick and tired: the compromised health of social assistance recipients and the working poor in Ontario. Toronto (ON): The Community Social Planning Council of Toronto (CSPC-T); 2009.

13. Lightman E, Herd D, Mitchell A. Precarious lives: work, health and hunger among welfare recipients in Toronto. J Policy Prac. 2008;7(4):242-59.

14. Vozoris N, Davis B, Tarasuk V. The affordability of a nutritious diet for households on welfare in Toronto. Can J Public Health. 2002;93(1):36-41.

15. Riches G. Food banks and the welfare crisis. Ottawa (ON): Lorimer; 1986.

16. Kirkpatrick SI, Tarasuk V. Adequacy of food spending is related to housing expenditures among lower-income Canadian households. Public Health Nutr. 2007;10(12);1464-73.

17. Williams PL, Johnson CP, Kratzmann ML, Johnson CS, Anderson BJ, Chenhall C. Can households earning minimum wage in Nova Scotia afford a nutritious diet? Can J Public Health. 2006;97(6):430-4.

18. Tarasuk V, McIntyre L, Li J. Low-income women's dietary intakes are sensitive to the depletion of household resources in one month. J Nutr. 2007;137:1980-7.

19. Kirkpatrick SI, Tarasuk V. Food insecurity is associated with nutrient inadequacies 
among Canadian adults and adolescents. J Nutr. 2008;138:604-12.

20. Agriculture and Agri-Food Canada. Canada's action plan for food security: in response to the World Food Summit Plan for Action [Internet]. Ottawa (ON): Agriculture and Agri-Food Canada; 1998 [cited 2009 Oct 29]. Available from: http://www.agr.gc.ca /misb/fsec-seca/pdf/action_e.pdf

21. Dietitians of Canada. Community food security: position of Dietitians of Canada [Internet]. Toronto: Dietitians of Canada; 2007 [cited 2009 Apr 9]. Available from: http://www.dietitians.ca/Dietitians-View /Community-Food-Security.aspx

22. Dietitians of Canada. Individual and household food insecurity in Canada: position of Dietitians of Canada [Internet]. Toronto: Dietitians of Canada; 2005 [cited 2009 Apr 9]. Available from: http://www.dietitians.ca/Dietitians-View/Individual-and -Household-Food-Insecurity.aspx

23. Vogt J, Tarasuk V. Analysis of Ontario sample in cycle 2.2 of the Canadian Community Health Survey, 2004 [Internet]. Ontario: Public Health Research, Education and Development; 2007 [cited 2009 Jan 8]. Available from: http://www.phred-redsp .on.ca/CCHSReport.htm

24. Statistics Canada. 2006 Community profiles census division [Internet]. Ottawa (ON): Statistics Canada; 2009 [cited 2009 Dec 3]. Available from: http://www12.statcan.ca/ census-recensement/2006/dp-pd/prof/92 $-591 /$ index.cfm

25. Lacey A, Luff D. Qualitative data analysis [Internet]. Nottingham (UK): The NIHR Research Design Service for the East Midlands; 2007 [updated 2009; cited 2009 Oct 29]. Available from: http://www.rds -eastmidlands.org.uk/resources/cat_view /13-resource-packs.html?start $=5$

26. Srivastava A, Thomson SB. Framework analysis: a qualitative methodology for applied policy research. JOAAG. 2009;4(2):72-9.

27. La Pelle N. Simplifying qualitative data analysis using general purpose software tools. Field Method. 2004;16(1):85-108.
28. Ryan GW. Using a word processor to tag and retrieve blocks of text. Field Method. 2004;16(1):109-30.

29. Teron AC, Tarasuk V. Charitable food assistance: what are food bank users receiving? Can J Public Health. 1999;90(6):382-4.

30. Irwin JD, Ng VK, Rush TJ, Nguyen C, He M. Can food banks sustain nutrient requirements? A case study in Southwestern Ontario. Can J Public Health. 2007;98(1):17-20.

31. Tse C, Tarasuk V. Nutritional assessment of charitable meal programmes serving homeless people in Toronto. Public Health Nutr. 2008;11(12):1296-305.

32. Hamelin AM, Mercier C, Bedard A. Discrepancies in households and other stakeholders viewpoints on the food security experience: a gap to address. Health Educ Res. 2010;25(3):401-2.

33. Hamelin AM, Beaudry M, Habicht JP. Characterization of household food insecurity in Québec: food and feelings. Soc Sci Med. 2002;54:119-32.

34. McIntyre L, Glanville NT, Raine KD, Dayle JB, Anderson B, Battaglia N. Do low-income lone mothers compromise their nutrition to feed their children? CMAJ 2003;168:686-91.

35. McIntyre L, Glanville NT, Officer S, Anderson B, Raine KD, Dayle JB. Food insecurity of low-income lone mothers and their children in Atlantic Canada. Can J Public Health. 2002; 93(6):411-5.

36. Tarasuk V, Maclean H. The food problems of low income single mothers: an ethnographic study. Can Home Econ J. 1990;40:76-82.

37. Riches G. Food banks and food security: welfare reform, human rights and social policy. Lessons from Canada? Soc Policy Admin. 2002;36(6):648-63.

38. Northumberland United Way. Community matters: community consultation final report [Internet]. Cobourg (ON); 2006 [cited 2010 Aug 25]. Available from: http://www.cobourg.unitedway.ca/Local _images/cobourg/CommunityMatters.pdf
39. Northumberland Poverty Reduction Action Committee. Report from the Northumberland Poverty Reduction Action Committee community action day. Cobourg (ON): Northumberland Poverty Reduction Action Committee; 2008.

40. Garasky S, Fletcher CN, Jensen HH. Transiting to work: the role of private transportation for low-income households. J Consum Aff. 2006;40(1):64-89.

41. Bostock L. Pathways of disadvantage? Walking as a mode of transportation among low-income mothers. Health Soc Care Community. 2000;9(1):11-8.

42. Perez CE. Fruit and vegetable consumption. Health Rep. 2002;13(3):23-31.

43. Subar AF, Heimendinger J, Patterson BH. Fruit and vegetable intake in the United States: the baseline survey of the Five-A-Day for Better Health Program. Am J Health Promot. 1995;9(5):352-60.

44. Xie B, Gilliland FD, Li YF, Rockett HRH. Effects of ethnicity, family income, and education on dietary intake among adolescents. Prev Med. 2003;36:30-40.

45. Giskes K, Turrell G, Patterson C, Newman B. Socioeconomic differences among Australian adults in consumption of fruit and vegetables and intakes of vitamins $\mathrm{A}, \mathrm{C}$ and folate. J Hum Nutr Diet. 2002;15:375-85.

46. Mishra G, Ball K, Arbuckle J, Crawford D. Dietary patterns of Australian adults and their association with socioeconomic status: results from the 1995 National Nutrition Survey. Eur J Clin Nutr. 2002;56:687-93.

47. Reicks M, Randall RL, Haynes BJ. Factors affecting consumption of fruits and vegetables by low-income families. J Am Diet Assoc. 1994;94(11):1309-11.

48. Kirkpatrick S, Tarasuk V. The relationship between low income and household food expenditure patterns in Canada. Public Health Nutr. 2003;6(6):589-97.

49. Health Canada. Eating well with Canada's Food Guide [Internet]. Ottawa (ON): Health Canada; 2009 [cited 2009 Jan 7]. Available 
from: http://www.hc-sc.gc.ca/fn-an/food -guide-aliment/index-eng.php

50. Wilkinson R, Marmot M, editors. Social determinants of health: the solid facts. 2nd ed [Internet]. Copenhagen (DK): World Health Organization; 2003 [cited on 2009 Dec 3]. Available from: http://www.euro .who.int/DOCUMENT/E81384.PDF

51. Raphael D. Health effects of economic inequality. Can Rev Soc Policy. 1999;44:25-40.

52. Raphael D. Health inequalities in Canada: current discourses and implications for public health action. Crit Public Health. 2000;10:193-216.

53. Raphael D. Poverty, income inequality, and health in Canada [Internet]. Toronto (ON): The CSJ Foundation for Research and Education; 2002 [cited 2009 Dec 3]. Available from: http://www.socialjustice .org/uploads/pubs/PovertyIncomeInequalityandHealthinCanada.pdf

54. Commission on Social Determinants of Health. Closing the gap in a generation: health equity through action on the social determinants of health. Final report of the Commission on Social Determinants of Health. Geneva $(\mathrm{CH})$ : World Health Organization; 2008. Available from: http:// www.who.int/social_determinants/thecommission/finalreport/en/index.html 